\title{
Estimating ozone risks using forest monitoring networks-results for science, policy, and society
}

\author{
Antonella Cristofori • Giovanni Bacaro • Mauro Confalonieri • Fabiana Cristofolini • \\ Luisa Frati • Francesco Geri • Elena Gottardini • Gabriele Tonidandel • Fabio Zottele • \\ Marco Ferretti
}

Received: 30 May 2014 / Accepted: 10 November 2014 / Published online: 16 December 2014

(C) INRA and Springer-Verlag France 2014

\begin{abstract}
- Key message Few integration steps (adding low-cost ozone measurements, link to existing conventional monitors, joint data processing) transformed the traditional forest monitoring network into a multifunctional infrastructure producing information relevant for estimating risk to vegetation and human health
\end{abstract}

\footnotetext{
Handling Editor: Pasi RAUTIO

Contribution of the co-authors Antonella Cristofori contributed to design the experiment, running field work, and write the paper; Giovanni Bacaro contributed to model ozone concentrations and write the paper; Mauro Confalonieri contributed to organize field work and write the paper; Fabiana Cristofolini contributed to design the experiment, running field work, and write the paper; Luisa Frati contributed to model ozone concentrations, derive and map ozone risk for population, and write the paper; Francesco Geri contributed to map ozone concentrations and write the paper; Elena Gottardini contributed to design the experiment, running field work, coordinating the research project, and write the paper; Gabriele Tonidandel contributed to collect ozone concentration data and write the paper; Fabio Zottele contributed to spatialize temperature data and write the paper; Marco Ferretti contributed to design the experiment, supervise the work, and write the paper.
}

Electronic supplementary material The online version of this article (doi:10.1007/s13595-014-0440-y) contains supplementary material, which is available to authorized users.

A. Cristofori $(\triangle) \cdot$ F. Cristofolini $\cdot$ E. Gottardini

Sustainable Agro-ecosystems and Bioresources Department,

Research and Innovation Centre, Fondazione Edmund Mach, Via E.

Mach 1, 38010 San Michele all'Adige, TN, Italy

e-mail: antonella.cristofori@fmach.it

F. Cristofolini

e-mail: fabiana.cristofolini@fmach.it

E. Gottardini

e-mail: elena.gottardini@fmach.it

G. Bacaro $\cdot$ L. Frati $\cdot$ F. Geri $\cdot$ M. Ferretti

TerraData environmetrics, Via L. Bardelloni 19,

58025 Monterotondo M.mo, GR, Italy
- Context Traditionally, forest monitoring networks have been designed to assess status and trends of forest condition. We argue that they can help providing answers to a much broader range of questions for science, policy, and society. Here, we concentrate on the example of ground-level ozone pollution. - Aims The aim of this study is to demonstrate the value of present forest monitoring networks as infrastructures that with few integration steps - can provide important data and information to estimate the risk posed by ground-level ozone to vegetation and human health.

- Methods We measured ozone concentration by passive samplers at the local (Trentino, northern Italy) plots of the ICP Forests Level I network over the period 2007-2011. By integrating these data with those from conventional ozone monitors (mostly located in urban areas), we (i) obtained an even distribution of air quality measurements over the investigated area, (ii) estimated international exposure indicators for vegetation and human population, and (iii) obtained data allowing geostatistical modeling and mapping of ozone concentrations, exposure, and associated potential risk.

- Results Mean May-July ozone concentration ranged from 58 to $169 \mu \mathrm{g} \mathrm{m}^{-3}$, depending on forest site and year. Modeling

\author{
G. Bacaro \\ e-mail: bacaro@unisi.it \\ L. Frati \\ e-mail: frati@terradata.it \\ F. Geri \\ e-mail: geri@terradata.it \\ M. Ferretti \\ e-mail: ferretti@terradata.it
}

G. Bacaro

CNR-IRPI, Istituto di Ricerca per la Protezione Idrogeologica, Via Madonna Alta 126, 06128 Perugia, Italy 
and mapping (root-mean-square deviation $($ RMSD) $=$ $12.31 \mathrm{\mu g} \mathrm{m}^{-3}$ ) provided evidence that the risk threshold for vegetation in terms of AOT40 was exceeded in large parts (90\%) of the study area, and frequently even by two times, depending on the year. With respect to population, up to $43 \%$ of the dwellers were exposed to medium-high risk of exceedances of the information threshold.

- Conclusion Ozone measurements carried out at the ICP Forests Level I forest monitoring network permitted mapping ozone levels and the estimation of possible risk for vegetation and human health. Forest monitoring networks can be seen as infrastructures that can be useful to address a wide range of environmental issues and with a much broader scope than their original one.

Keywords Potential risk · Directive 2008/50/EC . Vegetation $\cdot$ Human health $\cdot$ Modeling $\cdot$ Mapping

\section{Introduction}

Tropospheric ozone $\left(\mathrm{O}_{3}\right)$ originates from photochemical reactions involving primary air pollutants such as nitrogen oxides (NOx, mostly emitted by human activities) and volatile organic compounds (VOC, from both anthropogenic and biogenic emission) (The Royal Society 2008). Ozone has been frequently reported to cause severe risks to a variety of targets, including forest vegetation (Leisner and Ainsworth 2012) and human health (WHO 2000). In Europe, the Directive 2008/50/ EC (2008/50/EC 2008) sets acceptable limits for ozone concentration and exposure to protect human health and vegetation, for which thresholds are also defined by UNECE (CLRTAP 2004). These limits provide the basis under which national and regional regulatory agencies operate to identify areas where limits are exceeded and to undertake countermeasures or remedial actions. Information about the amount of the

\section{G. Bacaro}

BIOCONNET, Biodiversity and Conservation Network, Department of Life Sciences, University of Siena, Via P.A. Mattioli 4, 53100 Siena, Italy

M. Confalonieri

Forests and Fauna Service, Autonomous Province of Trento, Via G.B. Trener 3, 38121 Trento, Italy

e-mail: mauro.confalonieri@provincia.tn.it

\section{G. Tonidandel}

Environmental Protection Agency, Autonomous Province of Trento, Piazza Vittoria, 5 - 38122 Trento, Italy

e-mail: gabriele.tonidandel@provincia.tn.it

\section{F. Zottele}

Geographic Information System, Centre for Technology Transfer, Fondazione Edmund Mach, Via E. Mach 1, 38010 San Michele all'Adige, TN, Italy

e-mail: fabio.zottele@fmach.it target resource (e.g., population, forests) exposed to potentially harmful ozone concentration over a given region is therefore important to assess the potential risk and "benefit from the provision of high resolution maps" which "are essential for defining the communities most at risk" (Coyle et al. 2002). Such information, however, can be obtained only after an estimation process, which is constrained by the availability of ozone data and/or the prediction ability and applicability of models. This is particularly true when considering remote areas. Here, risk assessment is constrained by three main interrelated aspects: first, measurement of ground-level ozone is possible and/or affordable on a very limited number of sites. Even when available, measured data may have low spatial and/or temporal resolution. Second, it is known that ozone concentration in rural/remote sites is in general higher than those of urban areas, due to lack of chemical scavenging and reduced nighttime ozone depletion (the Royal Society 2008). In contrast, most of conventional monitors are located in urban areas, and - given the above pattern - they generate data that cannot be readily used to infer ozone risk to forests. Third, measured data at individual sites cannot be readily extrapolated over the target region in order to infer a possible risk. These constrains make modeling an important approach for risk assessment. Modeling ambient air quality has a long history (e.g., Kalenderski and Steyn 2011), and ozone photochemical deterministic models have been developed both at large- and local-scale. However, up to now, large-scale deterministic models are typically available with a too coarse spatial resolution (e.g., 50×50-km EMEP), not suited for the local-scale risk assessment (EEA 2009). On the other hand, even when developed at the local-scale (e.g., TECHNE Consulting s.r.l. 2006), photochemical models are data intensive and expensive to keep updated. In addition, scientific understanding of the physical and chemical processes may be incomplete for a given region, either in principle or in practice (Kalenderski and Steyn 2011). As a result, statistical and geostatistical modeling can be an option, and several attempts exist in this respect (e.g., Loibl et al. 2004).

Permanent networks of forest-condition monitoring plots have been installed on a systematic basis since the 1980s in Europe (Ferretti and Fischer 2013). They cover remote and forested areas, are georeferenced, and represent a convenient infrastructure for all those information needs that require an even spatial coverage, like the assessment of ozone pollution. Here, we present a study based on 5-year integrated data collection (different sources: passive sampling at forest sites and conventional monitors in urbanized areas), geostatistical modeling and mapping approach to produce "basic" spatial information of ozone data for a montane area in northern Italy, province of Trento (Fig. 1). In this area, ozone is originated in part by precursors from local sources (motorways and urban areas in the valley bottoms) and partly imported during the afternoon by air movements from the nearby heavily 
urbanized Po valley and Lombardy. A possible contribution of biogenic emission cannot be excluded, although no data was available to estimate its actual importance in the area. The local systematic ICP Forests Level I monitoring network (Lorenz and Fischer 2013) was equipped with passive samplers and integrated with the network of automatic analyzers of the Environmental Protection Agency, Autonomous Province of Trento (APPA). This approach provides the basis (i) to cope with the constrained condition of ozone data availability typical of many montane regions in Europe (e.g., Sanz et al. 2007) and (ii) to functionally connect the higher spatial resolution of the passive sampling network with the higher time resolution of the conventional monitors. The aims were (i) to provide spatially explicit estimates of the risk posed by ozone to vegetation and human health and, by this mean, (ii) to provide a proof of the potential of traditional forest monitoring networks not only for forest science (risk for potential impact of ozone on forests) but also for policy and the society at large extent (risk for seminatural vegetation and human health), demonstrating that multifunctionality of forest monitoring networks can be of great help in reconciling forest monitoring with environmental and societal needs (Ferretti et al. 2013).

\section{Materials and methods}

\subsection{Study concept}

The passive sampling network was installed in 2007 and was operational up to 2011. It covered forest areas, with passive samplers located in open areas or clearings nearby the plots of the systematic $(15 \times 18 \mathrm{~km})$ Level I monitoring network, at a mean altitude of $1318 \mathrm{~m}$ a.s.l. This network was designed in order to ensure an even coverage of the remote and forest areas (Fig. 1), thus complementing the conventional monitors, which are located in urban/ residential environments, at a mean altitude of $213 \mathrm{~m}$ a.s.1. (only exception: Monte Gaza, $1601 \mathrm{~m}$ a.s.1.). Provided their different nature and time resolution, data from passive sampling and conventional monitors were then integrated and used jointly for (i) geostatistical modeling of ozone concentration and (ii) derivation of consistent indicators for the protection of human population and vegetation. On this basis and with the further integration of temperature data, land use, and census, $1 \times 1$ $\mathrm{km}$ resolution maps were prepared, and percentage of population and vegetation exposed to possible exceedance of threshold values was calculated.

\subsection{Study area}

The study domain is the Trento province $\left(6207 \mathrm{~km}^{2}\right.$, northern Italy) (Fig. 1), with elevations ranging from the $66 \mathrm{~m}$ a.s.l. of the valley bottom (Garda Lake) to the $3769 \mathrm{~m}$ a.s.l. of Monte Cevedale. Fifty-five percent of the surface is covered by forests, $27 \%$ by crops and pasture, and only $3 \%$ is urbanized (CORINE Land Cover 2000, retrieved by http://www.eea. europa.eu/themes/landuse/clc-download; access at 1/12/ 2012). The largest city in the region, Trento, and the main lines of traffic, responsible for most of ozone precursors, are located in the bottom of the Adige Valley. Climate is prevalently humid oceanic-temperate, with cold and dry winters and fresh and rainy summers. Annual precipitation ranges between 800 and $1500 \mathrm{~mm}$, with two maxima in spring

Fig. 1 The Italian province of Trento (left) with ozone monitoring sites: passive sampling (triangles) and automatic units (circles)

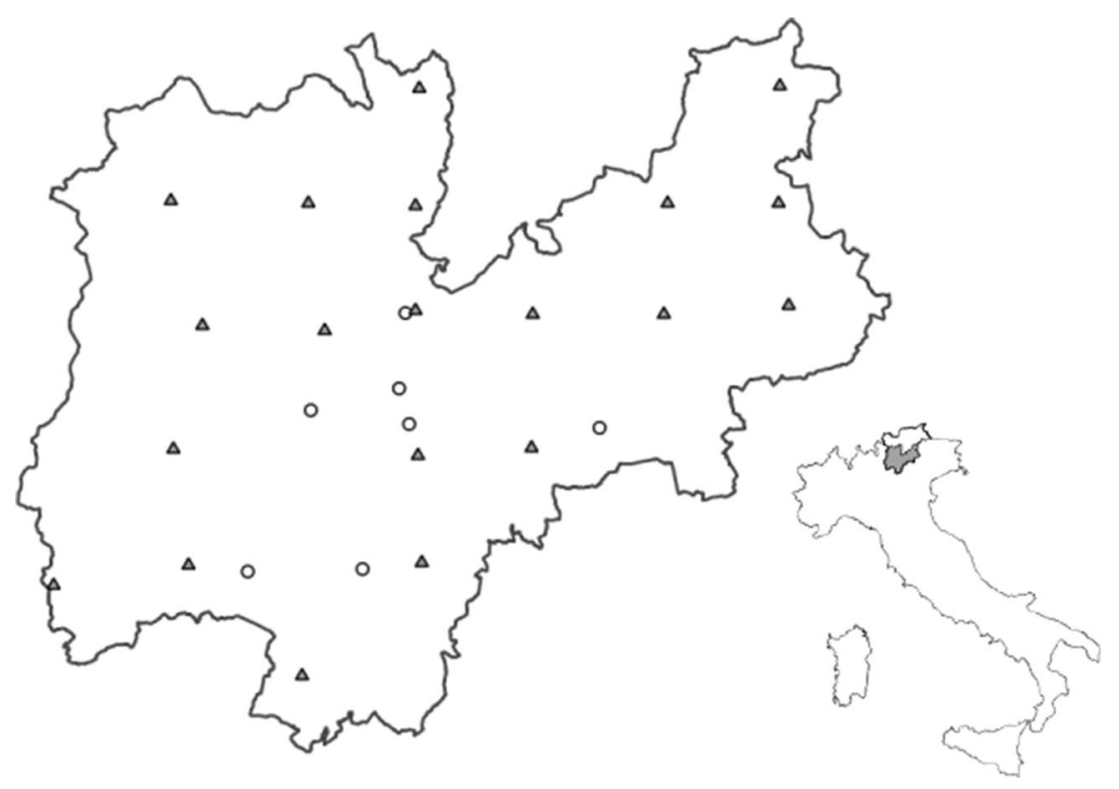


and autumn. Annual mean temperature varies between 8 and $12{ }^{\circ} \mathrm{C}$ (Eccel and Saibanti 2005).

\subsection{Input data for modeling approaches}

Input data for modeling included geographical localization and elevation, land use data, spatially explicit modeled temperature data, ozone data from passive sampling and automatic units, and demographic data. Ozone concentration data were collected by eight UV-photometric analyzers with hourly measurement (APPA; $n=7$ urban-suburban automatic, $n=1$ mountain) and 15-20 sites equipped by diffusive samplers, with weekly exposure time (passam ag, Männedorf, Switzerland; $n=15$ in 2007; $n=20$ in 2008-2011), exposed in open areas nearby the forest plots for 13 weeks in a period ranging from the end of April to the start of August during the years 2007-2011 (Fig. 1; Online Resource 1). Crosscalibration of passive samplers and automatic analyzers was performed by means of colocated devices (for details see Gottardini et al. 2010).

Weekly mean temperature maps were calculated from hourly temperature maps at a $250-\mathrm{m}$ spatial resolution and then upscaled to the $1-\mathrm{km}$ resolution grid selected for the modeling approach (Gottardini et al. 2010), using the mean value as a linear operator on the pixel values. Maps were modeled by regression-kriging (RK) (Hengl et al. 2007) on hourly mean temperature records from 113 meteorological stations (property of Fondazione Edmund Mach and Meteotrentino).

Based on the data provided by the Statistics Service of the Autonomous Province of Trento, Trentino counted 477,010 dwellers in 2001 and 524,826 in 2010, with a spatial distribution almost unchanged between the two surveys. In particular, the highest population density was found at elevation $<500 \mathrm{~m}$ a.s.l. Population coverage was estimated for each $1 \times 1-\mathrm{km}$ grid cell (the same used for modeling ozone concentration and potential risk) in proportion of the percentage of the surface of each cadastral section falling into the given cell and assuming an homogeneous distribution of the population.

\subsection{Geostatistical analysis and modeling}

Five annual models were developed, one for each year, 2007-2011 (for details see Online Resource 2). Predictive geostatistical linear models were evaluated to estimate mean ozone concentration in $1 \times 1-\mathrm{km}$ grid cells across the entire study domain. Tests for normality and, when necessary, Box-Cox transformation (Legendre and Legendre 1998) were preliminarily conducted on each data series, and subsequently, a generalized linear model was built. Starting from a full model, the final parsimonious, reduced model was identified according to a step-wise procedure, with explanatory variables (elevation and temperatures) chosen through the minimization of the $(\log )$ likelihood and the Akaike Information Criterion (AIC) (Cristofori et al. 2012). The low number of included explanatory variables was defined considering the low number of ozone samplers compared to the high number of coefficients to estimate. Cross-validation statistics by leave-one-out procedure was used to assess the bias, and the accuracy of the final spatial model was evaluated by root-mean-square deviation (RMSD). Universal kriging (Krige 1976) was then applied in order to predict mean ozone concentrations in each $1 \times 1-\mathrm{km}$ grid cell across the whole Trento province, for the considered period (2007-2011).

\subsection{Estimation of potential exceedances of target thresholds} for ozone exposure

As for vegetation, ozone accumulated over a threshold of $80 \mu \mathrm{g} \mathrm{m}^{-3}$ (=40 parts per billion, AOT40) was the indicator defined to evaluate potential risk due to ozone (2008/50/EC 2008; CLRTAP 2004). AOT40 was estimated for each $1 \times 1$ $\mathrm{km}$ cell on the basis of mean concentration data and by a simple linear model (Ferretti et al. 2012a). In order to identify and quantify the vegetation area potentially at risk, the estimated AOT40 was associated to CORINE Land Cover codes for forests (3.1) and seminatural vegetation (3.2). Evaluation was referred to three categories of potential relative risk: AOT $40<$ risk threshold (RT), RT $<$ AOT40 $<2 \mathrm{RT}$, AOT40 $>$ 2RT. RTs considered in this study were those set by the Directive 2008/50/EC (6000 and 18,000 $\mathrm{mg} \mathrm{m}^{-3} \mathrm{~h}^{-1}$, longterm objective and target value, respectively) and by UNECE (10,000 $\mu \mathrm{g} \mathrm{m}^{-3} \mathrm{~h}^{-1}$, critical level; CLRTAP 2004).

For the population, the information threshold (IT; $180 \mu \mathrm{g} \mathrm{m}^{-3}$, averaged over $1 \mathrm{~h}$ ) for human health, set by the Directive 2008/50/EU, was considered, being the most utilized threshold adopted by public agencies to protect sensitive sections of population. The probability $P$ of exceedances of the IT was estimated for each range of $20 \mu \mathrm{g} \mathrm{m}^{-3}$ of weekly mean ozone concentration, $M$, as measured by conventional monitors. Weekly $M$ ranges of $20 \mu \mathrm{g} \mathrm{m}^{-3}$ were compared with the number of weekly exceedances of the IT registered within the same weeks. For each $M$ range, the ratio between the number of weeks with exceedances and the total number of weeks considered returns the $P$ value. The probability is null $(P=0)$ for values lower than a certain value of $M, M_{p=0}$, and grows with increasing values of $M$ to reach a maximum $(P=1)$ at $M_{p=1}$. The lower $P$, the lower the probability to have exceedance of the information threshold and therefore the risk for harmful exposure to ozone. Table 1 reports $P$ values for different $M$ ranges. The probability of exceedances was 
Table 1 Probability of weekly exceedances of the information threshold $\left(180 \mu \mathrm{g} \mathrm{m}^{-3}\right)$ related to each concentration range $\left(M, \mu \mathrm{g} \mathrm{m}{ }^{-3}\right)$ at sites equipped with automatic analyzers, mean exceedance probability ( \pm standard deviation) for valley floor only (Monte Gaza excluded) and all sites

\begin{tabular}{|c|c|c|c|c|c|c|}
\hline Site & $M<60$ & $60<M<80$ & $80<M<100$ & $100<M<120$ & $120<M<140$ & $140<M<160$ \\
\hline Borgo Valsugana & 0 & 0.04 & 0.44 & 1.00 & - & - \\
\hline Trento Gardolo & 0 & 0.10 & - & - & - & - \\
\hline Monte Gaza & 0 & 0 & 0 & 0.08 & 0.38 & 0.50 \\
\hline Trento Parco S. Chiara & 0 & 0.05 & 0.20 & 0.60 & - & - \\
\hline Piana Rotaliana & 0 & 0.15 & 0.35 & 1 & - & - \\
\hline Riva del Garda & 0 & 0.05 & 0.58 & 1 & - & - \\
\hline Rovereto Largo Posta & 0 & 0 & 0.05 & 0.56 & - & - \\
\hline Grumo S. Michele a/A & 0 & 0.13 & 0.50 & - & - & - \\
\hline Valley floor & 0.0 & $0.07( \pm 0.05)$ & $0.35( \pm 0.20)$ & $0.83( \pm 0.23)$ & - & - \\
\hline All sites & 0.0 & $0.06( \pm 0.05)$ & $0.30( \pm 0.22)$ & $0.71( \pm 0.37)$ & 0.38 & 0.50 \\
\hline
\end{tabular}

calculated only for grid cells with elevations $<500 \mathrm{~m}$ a.s.l. and number of residents $>0$.

\subsection{Quality assurance}

Data completeness was verified for each automatic analyzer. Mean completeness was $94.9 \%$ (range 60.5-100\%); data series (site/year) with a completeness $<90 \%$ were discarded (four out of 31). Reliability of ozone concentration data provided by passive sampling was evaluated by parallel measurements in close proximity of the conventional monitors. Raw hourly mean temperatures used for the modeling were validated using standard data quality routines. Reliability of modeled temperatures was further tested by comparison with data measured by temperature micro-dataloggers (FT-800/System, Econorma s.a.s., Treviso, Italy), positioned in each ozone measurement site.

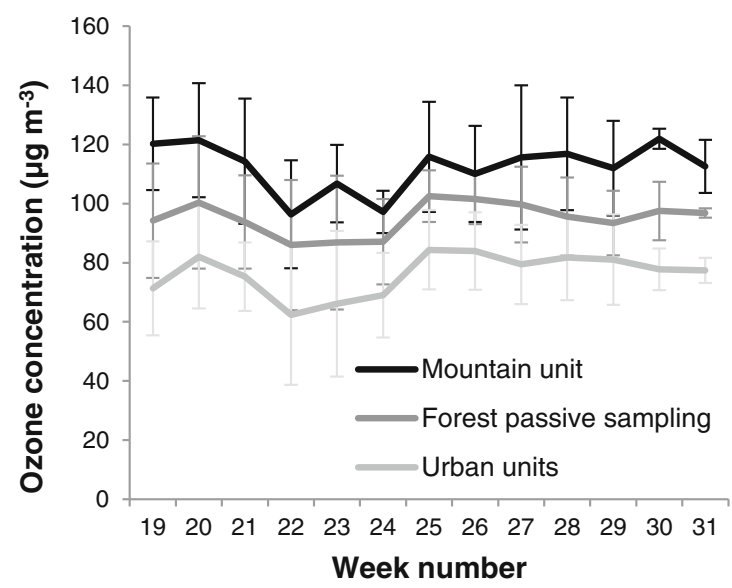

Fig. 2 Time course of mean ozone concentrations for the considered weeks (left) and for the daytime (right). Mean concentration over 20072011 is represented by week for the mountain automatic unit $(1601 \mathrm{~m}$ a.s.1.), the forest passive sampling sites ( $n=15$ in 2007, 20 in 2008-2011;

\section{Results}

\subsection{Ozone concentration}

Seasonal and daily time course of mean ozone concentrations recorded by passive samplers and automatic units are reported in Fig. 2. Although the time course is consistent between the two methods, the mean values differ. Besides differing accuracy, this may depend on the location and elevation of the monitoring sites (Gottardini et al. 2010). The well-known pattern for which urban areas (mostly at the valley bottom) show lower ozone concentration than rural/montane areas (mostly at medium to high elevation) (The Royal Society 2008) was proven true also for the Trento Province. Moreover, comparing the daily course of hourly mean ozone concentration for low and high elevation automatic units, a clear reduction of nighttime

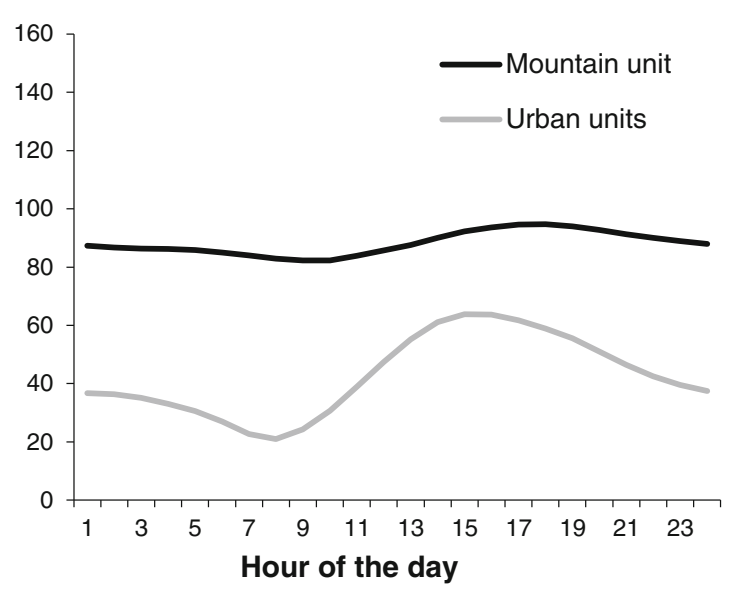

mean elevation $1318 \mathrm{~m}$ a.s.1.), and the urban-suburban automatic units $(n=7$, mean elevation $213 \mathrm{~m}$ a.s.1.); bars indicate the standard deviation among years (left). Daily development of the hourly mean of ozone concentration for a mountain and six urban units, referred to 2007 (right) 
Table 2 Description of explanatory variables (and their associated coefficients) included after stepwise selection involved in the reduced spatial model (in bold), built for each year within the study period

\begin{tabular}{|c|c|c|c|c|c|c|c|c|c|c|}
\hline \multirow[t]{2}{*}{ Year } & \multirow[t]{2}{*}{ Model } & \multirow[t]{2}{*}{ Intercept } & \multirow[t]{2}{*}{$X$} & \multirow[t]{2}{*}{$Y$} & \multirow[t]{2}{*}{ Elevation } & \multirow[t]{2}{*}{$T\left(^{\circ}\right)$} & \multicolumn{4}{|c|}{ Spatial parameters } \\
\hline & & & & & & & $\sigma^{2}$ & $\varphi$ & $\tau^{2}$ & AIC \\
\hline \multirow[t]{2}{*}{2007} & Total & 2047.773 & 0.0000 & -0.0004 & 0.0647 & 5.7128 & 4.5231 & $25,348.78$ & 166.0890 & $191.5 /-87.73$ \\
\hline & Reduced & -35.0896 & & & 0.0509 & 4.2651 & 202.76 & $28,511.46$ & 133.6205 & $191.7 /-89.83$ \\
\hline \multirow[t]{2}{*}{2008} & Total & 2330.699 & -0.0002 & -0.0004 & 0.0354 & 2.1798 & 1.27 & $2,088,596$ & 117.6 & $175.9 /-79.96$ \\
\hline & Reduced & 38.7184 & & & 0.0256 & 1.5598 & 613.4 & 44,516 & 72.31 & $177.7 /-82.87$ \\
\hline \multirow[t]{2}{*}{2009} & Total & 1891.927 & 0.0001 & -0.0004 & 0.0781 & 8.1257 & 0.0000 & 0 & 106.1873 & $211.1 /-97.54$ \\
\hline & Reduced & -57.0797 & & & 0.0594 & 5.5266 & 319.1 & 20,712 & 38.81 & $211.7 /-99.83$ \\
\hline \multirow[t]{2}{*}{2010} & Total & 3976.102 & 0.0002 & -0.0008 & 0.0594 & 5.0465 & 349.9 & 6297 & 11.56 & $236.2 /-110.1$ \\
\hline & Reduced & -58.0542 & & & 0.0617 & 5.6568 & 846.4 & 16,252 & 78.46 & $239.5 /-113.7$ \\
\hline \multirow[t]{2}{*}{2011} & Total & 3056.203 & 0.0000 & -0.0006 & 0.0923 & 9.3345 & 0 & 0 & 294 & $237.6 /-110.8$ \\
\hline & Reduced & -191.771 & & & 0.1094 & 11.8085 & 724.3 & 15,542 & 70.95 & $236.9 /-112.5$ \\
\hline
\end{tabular}

$\sigma^{2}$ the signal variance, $\varphi$ range which indicates the distance at which the theoretical variogram reaches its maximum and represents the correlation function parameter, $\tau^{2}$ nugget which represents the intercept of the variogram and determines the conditional or measurement error variance, AIC Akaike Information Criterion, used to estimate model fitting

ozone depletion is demonstrated for the mountain site (Fig. 2).

The basic model features are reported in Table 2. The overall accuracy of the model, as estimated comparing measured and predicted ozone values by RMSD, is relatively high $\left(12.31 \mathrm{\mu g} \mathrm{m}^{-3}\right.$ against a mean value of $92 \mu \mathrm{g} \mathrm{m}^{-3}$ ). Figure 3 reports the comparison between predicted and measured ozone concentration after cross validation. Differences are almost within the expected measurement uncertainty (2013 revision; see http://www. passam.ch/ozone.htm). Predicted 2007-2011 average ozone concentration over the 13 weeks considered is shown in Fig. 4. The maps present the highest ozone concentrations $\left(>140 \mu \mathrm{g} \mathrm{m}^{-3}\right)$ on the western side of the province, while mean ozone concentrations $<100 \mu \mathrm{g} \mathrm{m}^{-}$ 3 are estimated for most of the province area. Concentrations are always lower in the valley bottoms and increase with elevation.

\subsection{Potential risk due to ozone}

Maps of potential ozone risk for vegetation over the period 2007-2011 and the percent area within each category of relative risk are reported in Fig. 5. All in all, only a small area of vegetation is estimated not at risk $(0.17 \%$ in the case of EU long-term threshold; $6.6 \%$ in the case of EU Target value). On the other hand, 93.4$99.8 \%$ of the area with forest and seminatural vegetation appear potentially at risk, with a considerable portion of vegetation exposed to AOT40 values higher than two times the risk threshold $(55.0 \%$ in the case of EU Target; $97.8 \%$ in the case of EU long-term).
Figure 6 illustrates the spatial distribution for the probability of exceedance of the information threshold for human population $\left(180 \mu \mathrm{g} \mathrm{m}^{-3}\right)$ for all the grid cells below $500 \mathrm{~m}$ a.s.l. This elevation limit was set to account for (i) the population distribution pattern and (ii) the probability distribution function that appears to be rather different for high-elevation sites. Exceedance of protection values varies year by year. In detail, between 57 and $92 \%$ of the resident population was exposed to a relatively low risk $(<30 \%)$ of exceedance of the information threshold, and between 0.02 and $43 \%$ was exposed to a medium risk (30-60\%). Only

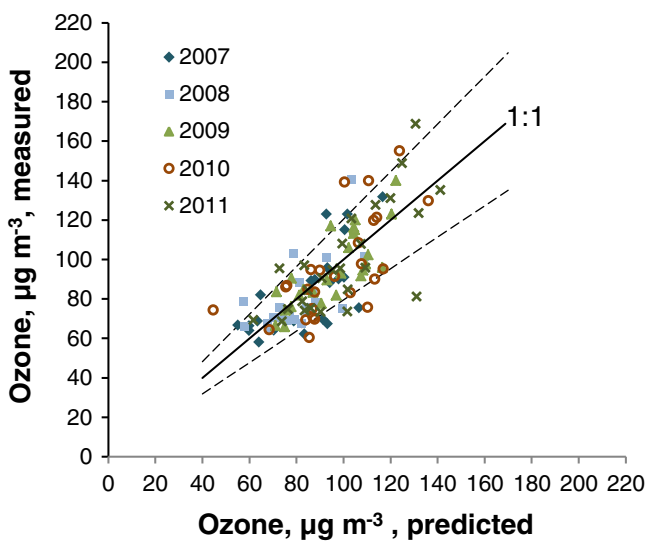

Fig. 3 Mean ozone concentration (in $\mu \mathrm{g} \mathrm{m}^{-3}$ ) per site and year (20072011). Ozone concentrations predicted by the geostatistical model are plotted against values measured by passive sampling. Solid line represents the bisector (1:1), while dashed lines show the uncertainty of measurement for passive samplers as declared by the manufacturer ( $20.5 \%$ for an ozone concentration $=80 \mu \mathrm{g} \mathrm{m}^{-3} ; 2013$ revision; http:// www.passam.ch/ozone.htm) 
Fig. 4 Ozone concentrations at $1 \times 1-\mathrm{km}$ resolution in Trentino, mean of a 13-week period, 2007 2011

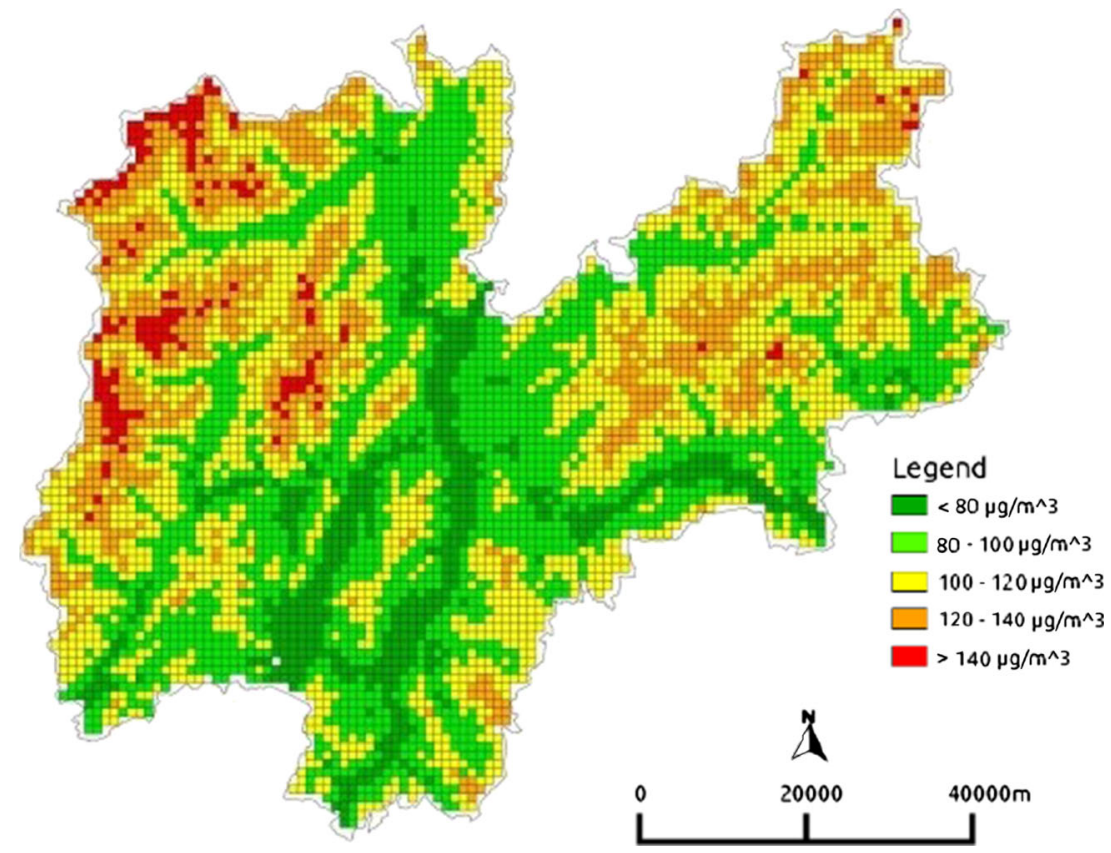

one single grid cell presented a high risk of exposure, in 2011 , with five residents $(0.002 \%)$. Within the study period, the higher percentage of residents exposed to medium or high exceedances was found for the year 2011 (43\%).
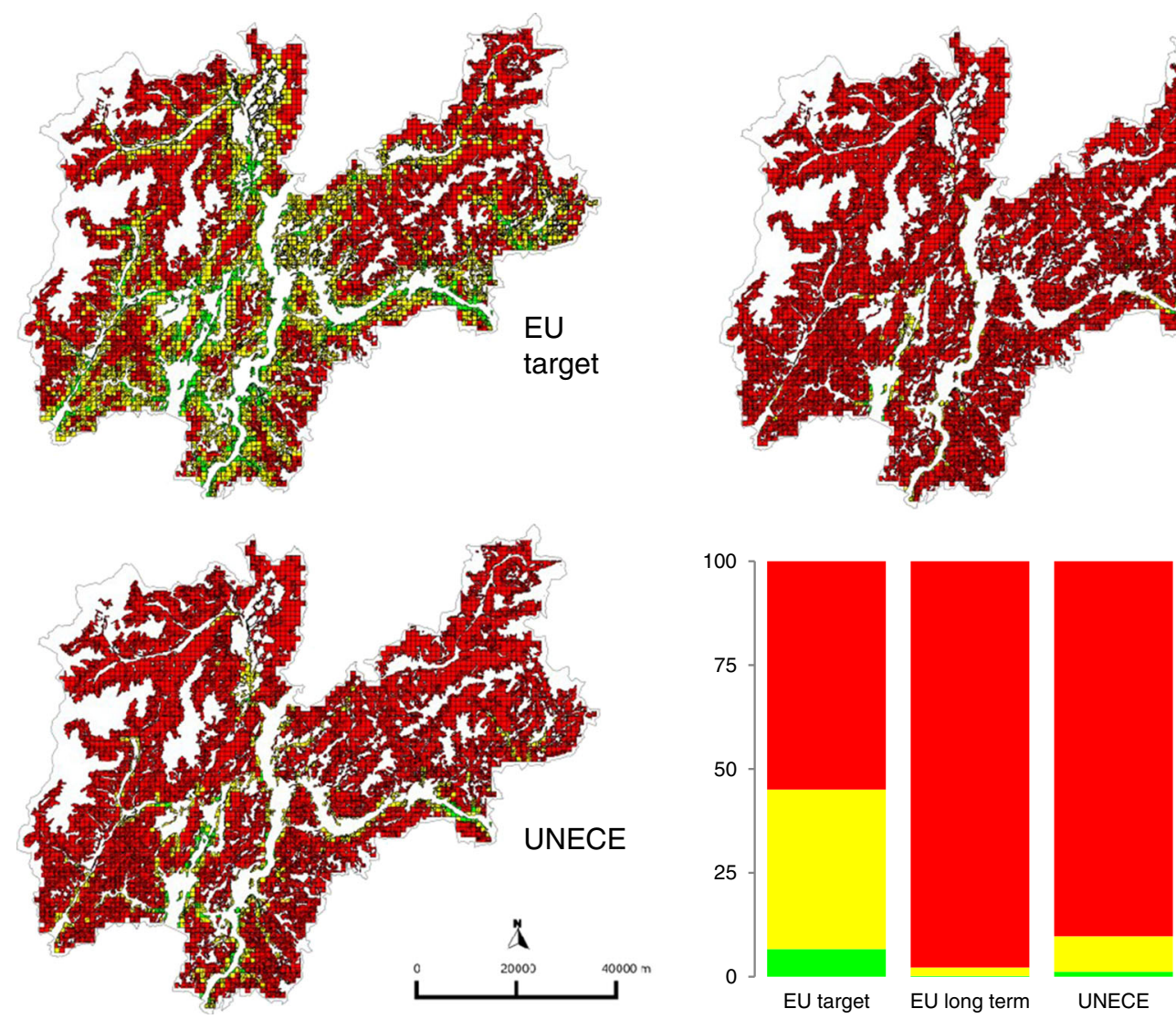

EU

Long term

EU target

EU long term

- >2 threshold

1-2 threshold

$-<1$ threshold

$6000 \mu \mathrm{g} \mathrm{m}^{-3} \mathrm{~h}$, respectively; top left and right) and the critical level of the UNECE Manual $\left(10,000 \mu \mathrm{g} \mathrm{m}^{-3} \mathrm{~h}\right.$; bottom left). On the bottom right, percentage of forest area for each risk category

period 2007-2011. Risk was estimated considering the target value fo 2010 and the long-term objective of Directive 2008/50/EC (18,000 and 

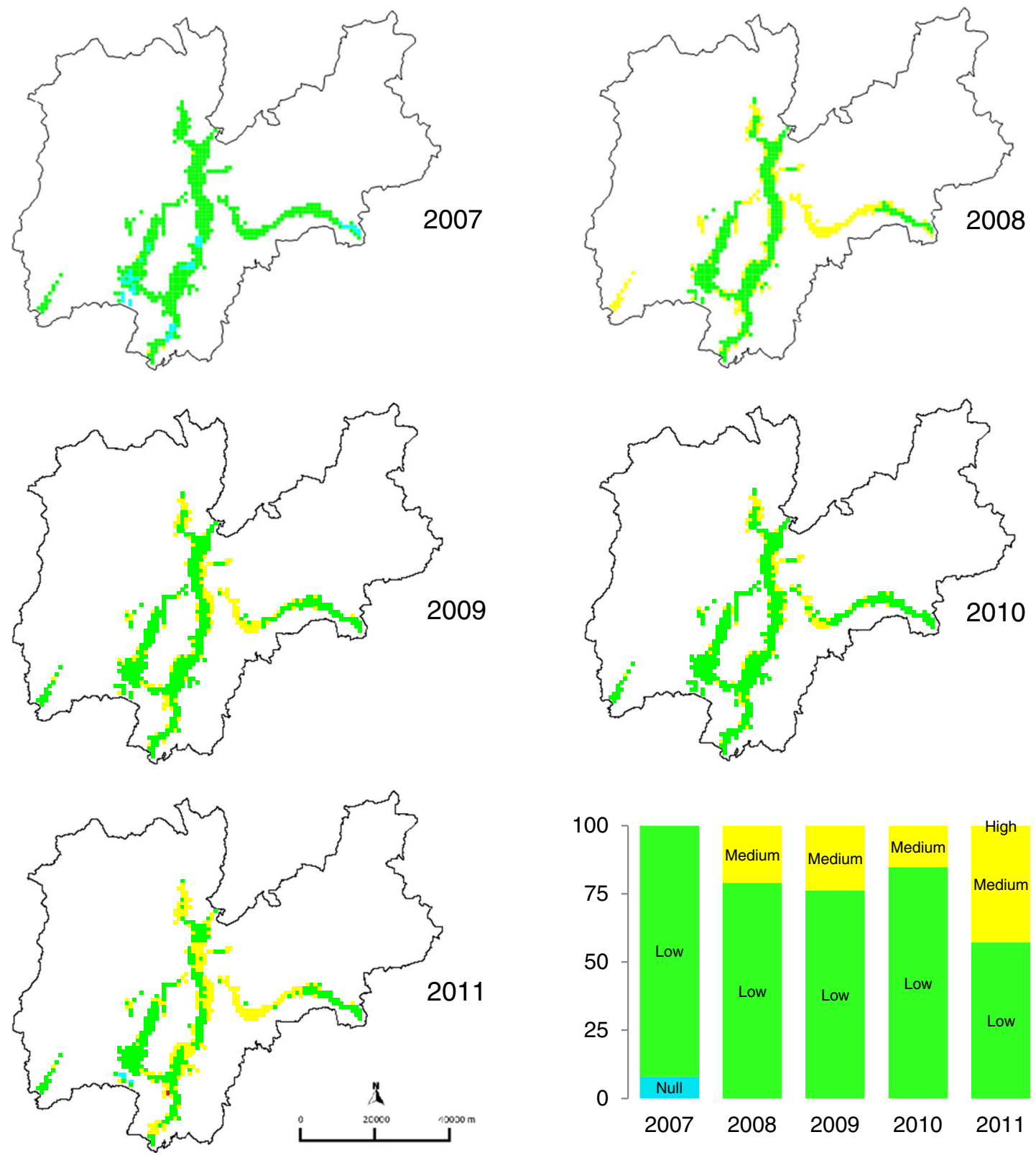

Fig. 6 Risk estimates for exceedances of the information threshold for human population (2007-2011): spatial distribution (annual maps) and percentage of population exposed (column chart). Probability of

\section{Discussion}

Estimating the potential risk that ozone poses to natural resources and human health requires concentration data as a basic input for modeling ozone levels across space. Both elements (concentration data and modeling) take advantage of evenly distributed and dense enough measurement networks.

In this paper, we evaluated the feasibility of, and the results obtained by, a modeling approach using available data (ozone and temperature data by existing stations and models, geographical data) and collecting low-cost data at the plots of

exceedances: null (light blue), low ( $<30 \%$, green), medium $(>40$ $60 \%$, yellow), and high $(>60 \%$, red $)$ (color figure online)

existing systematic forest monitoring network. Our results show that the geostatistical approach was able to model the mean ozone concentration with a reasonable level of uncertainty. Besides this, results provide concrete evidence of the value of existing forest monitoring infrastructures also when the goal (i.e., assessment of ozone pollution and risk for vegetation and human health) is rather different from their original one (i.e., monitoring forest condition). By means of the forest monitoring network, it was possible to address information needs related to the forest community (exposure to ozone measured at the site; input data for response, correlative studies of ozone impact on 
growth and health; Ferretti et al. 2012b) and to a larger group of potential data users (input data for modeling and subsequent estimates for e.g., potential risk for human health). In the same line, mapped ozone levels can be of value when ozone impacts on ecosystem services (Mills et al. 2013) are of concern. In a capsule, supplementing the existing plots with passive sampling and ensuring proper integration with other data sources (e.g., conventional monitors, existing temperature models) provided additional value to the original forest monitoring network.

There are, however, several elements that need improvement. From the technical point of view, the probability distribution function of risk threshold exceedance for human health requires to be adapted for high elevation areas. From a more general perspective, adequate communication and dissemination are necessary to make resource managers, decision makers, environmental protection agencies, local health authorities, and monitoring administrators aware of the considerable benefit that few integration steps can provide to the information potential of monitoring networks.

Another issue is the extent at which potential risk can actually result into real effects. Although addressing such an issue is out of the scope of this paper, it is worth mentioning that different factors may modify the actual response to ozone of plants and human beings. This is particularly true for vegetation, for which ozone uptake by foliage (rather than exposure) is considered more suited to evaluate the actual risk (e.g., Reich 1987). Since ozone uptake is controlled by stomatal conductance, actual risk for vegetation can differ from the potential risk inferred by e.g. AOT40 data (The Royal Society 2008). In particular, such a risk can be considerably lower than expected at sites subject to drought condition (e.g. Mediterranean sites). It is worth noting that, due to the local climate, most forests in Trentino experience fresh and rainy summer, with potentially scarce limitation for ozone uptake. Actually, preliminary data showed that time patterns of ozone flux and AOT40 are pretty similar (Ferretti et al. 2012b).

\section{Conclusion}

Ground-level ozone mean concentration was modeled over a $6207 \mathrm{~km}^{2}$ from data obtained by conventional monitors (mostly in urban areas) and passive sampling in remote sites of already existing forest condition monitoring networks. Cross validation revealed an overall agreement between estimated and measured values, with an estimated root-mean-square deviation (RMSD) of $12.31 \mathrm{\mu g} \mathrm{m}^{-3}$ against a mean value of $92 \mathrm{\mu g} \mathrm{m}^{-3}$. Our study provides evidence that Level I monitoring network is an infrastructure that not only can be useful within the forest community but also - with a few integration steps - may serve as a suitable framework to address a wide range of environmental concerns, including human health, even at local level.

We focused on the evaluation of the risks posed by ozone to forest and seminatural vegetation (which are of interest for forest and environmental resource managers) and human health (which is of interest of local health authorities). Based on the forest monitoring grid, we were able to estimate levels and extent of the potential risk, and this is indeed an important step for the environmental management. Whether this potential risk actually results into real effects is out of the scope of this paper and will be subject of further investigation.

The results presented here can be reinforced by more extensive testing at national and international level. This may help in strengthening the concept and improve predictive models. In a time when support for ecological monitoring is becoming increasingly difficult (e.g., Legg and Nagy 2006), demonstrating the multifunctionality of the existing infrastructure may also help in reconciling forest monitoring with environmental and societal needs.

Acknowledgments Forests and Fauna Service and Environmental Protection Agency of the Autonomous Province of Trento contributed to the realization of the project, in terms of funding, data sharing, and field work. This is the paper No. 6 originated by the Ozone EFFORT project (Ozone EFFect on FORests in Trentino).

Funding Funding was from Forests and Fauna Service and Environmental Protection Agency of the Autonomous Province of Trento.

\section{References}

2008/50/EC (2008) Directive 2008/50/EC of the European parliament and of the council of 21 May 2008 on ambient air quality and cleaner air for Europe. J Eur Union

CLRTAP (2004) Manual on methodologies and criteria for modelling and mapping critical loads and levels and air pollution effects, risks and trends, ECE Convention on Long-range transboundary air pollution; accessed on 13/05/2014 at the websites of the ICP mapping \& modelling and at the website of the coordination centre for effects

Coyle M, Smith RI, Stedman JR, Weston KJ, Fowler D (2002) Quantifying the spatial distribution of surface ozone concentration in the UK. Atmos Environ 36:1013-1024. doi:10.1016/S13522310(01)00303-X

Cristofori A, Cristofolini F, Gottardini E, Bacaro G, Geri F, Zottele F, Ferretti M (2012) Modellizzazione e spazializzazione delle concentrazioni di ozono e stima del rischio potenziale per la vegetazione. In: Gottardini et al. (eds) Ozono e foreste in Trentino-Risultati del progetto Ozone EFFORT 2007-2011. Fondazione Edmund Mach, San Michele all'Adige (TN), Italy. pp 45-64. ISBN: 978-88-7843-037-2. doi: 10.13140/2.1.4501.8568

Eccel E, Saibanti S (2005) Climatic setting of the Lavarone-Vezzena Plateau in the general context of Trentino. Studi Trent Sci Nat Acta Geol 82:111-121

EEA (2009) EMEP/EEA air pollutant emission inventory guidebook 2009. Technical guidance to prepare national emission inventories 2009. European Environment Agency, Luxembourg 
Ferretti M, Fischer R (2013) Forest Monitoring: methods for terrestrial investigations in Europe with an overview of North America and Asia. Developments in environmental science, vol 12. Elsevier, Oxford

Ferretti M, Cristofolini F, Cristofori A, Gerosa G, Gottardini E (2012a) A simple linear model for estimating ozone AOT40 at forest sites from raw passive sampling data. J Environ Monit 14:2238-2244. doi:10. 1039/c2em30137g

Ferretti M, Bacaro G, Brunialti G, Cristofolini F, Cristofori A, Frati L, Maccherini S, Gottardini E (2012b) Defogliazione ed accrescimento degli alberi nei siti di monitoraggio delle foreste in Trentino: relazione con fattori stazionali, nutrizionali, meteorologici ed ozono nel periodo 2005-2011. In: Gottardini et al. (eds) Ozono e foreste in TrentinoRisultati del progetto Ozone EFFORT 2007-2011. Fondazione Edmund Mach, San Michele all'Adige (TN), Italy. pp 107-132. ISBN: 978-88-7843-037-2 . doi: 10.13140/2.1.4501.8568

Ferretti M, Fischer R, Moffat J (2013) Terrestrial methods in forest monitoring: toward the next generation? In: Ferretti M, Fisher R (eds) Forest monitoring: methods for terrestrial investigations in Europe with an overview of North America and Asia. Developments in environmental science, vol 12. Elsevier, Oxford, pp 483-496

Gottardini E, Cristofori A, Cristofolini F, Ferretti M (2010) Variability of ozone concentration in a montane environment, northern Italy. Atmos Environ 44:147-152. doi:10.1016/j.atmosenv.2009.10.017

Hengl T, Heuvelink GBM, Rossiter DG (2007) About regression-kriging: from equations to case studies. Comput Geosci 33:1301-1315. doi: 10.1016/j.cageo.2007.05.001

Kalenderski S, Steyn DG (2011) Mixed deterministic statistical modelling of regional ozone air pollution. Environmetrics 22:572-586. doi:10.1002/env.1088
Krige DG (1976) A review of the development of geostatistics in South Africa. In: Guarascio $M$ et al (eds) Advanced geostatistics in the mining industry. Reidel, Dordrecht, Holland, pp 279-293

Legendre P, Legendre L (1998) Numerical ecology, 2nd edn. Elsevier Science B.V, Amsterdam

Legg CJ, Nagy L (2006) Why most conservation monitoring is, but need not be, a waste of time. J Environ Manag 78:194-199. doi:10.1016/ j.jenvman.2005.04.016

Leisner CP, Ainsworth EA (2012) Quantifying the effects of ozone on plant reproductive growth and development. Glob Chang Biol 18: 606-616. doi:10.1111/j.1365-2486.2011.02535.x

Loibl W, Bolhar-Nordenkampf HR, Herman F, Smidt S (2004) Modelling critical levels of ozone for the forested area of Austria modifications of the AOT40 concept. Environ Sci Pollut Res 11:171-180. doi:10. 1065/espr2004.03.187

Lorenz M, Fischer R (2013) Pan-European forest monitoring: an overview. In: Ferretti M, Fischer R (eds) Forest monitoring: methods for terrestrial investigations in Europe with an overview of North America and Asia. Elsevier Science Bv, Amsterdam, pp 19-32

Mills G, Wagg S, Harmens H (2013) Ozone pollution: impacts on ecosystem services and biodiversity. Centre for ecology and hydrology. Environment Centre Wales, Bangor

Reich P (1987) Quantifying plant response to ozone: a unifying theory. Tree Physiol 3:63-91. doi:10.1093/treephys/3.1.63

Sanz MJ, Calatayud V, Sanchez-Pena G (2007) Measures of ozone concentrations using passive sampling in forests of South Western Europe. Environ Pollut 145:620-628. doi:10.1016/j.envpol.2006.02.031

TECHNE Consulting s.r.l (2006) Studio modellistico sulla generazione e trasporto dell'ozono. N.Raccolta 13/05, pp.106. APPA, Trento

The Royal Society (2008) Ground-level ozone in the 21st century: future trends, impacts and policy implications. The Royal Society, London

WHO (2000) Air quality guidelines for Europe, vol 91, 2nd edn. WHO Regional Publications, European Series, Copenhagen 